This item was submitted to Loughborough's Research Repository by the author.

Items in Figshare are protected by copyright, with all rights reserved, unless otherwise indicated.

\title{
A new low-temperature hermetic composite edge seal for the fabrication of triple vacuum glazing
}

PLEASE CITE THE PUBLISHED VERSION

http://dx.doi.org/10.1016/j.vacuum.2015.06.024

\section{PUBLISHER}

(C) Elsevier Ltd.

\section{VERSION}

AM (Accepted Manuscript)

\section{PUBLISHER STATEMENT}

This work is made available according to the conditions of the Creative Commons Attribution-NonCommercialNoDerivatives 4.0 International (CC BY-NC-ND 4.0) licence. Full details of this licence are available at: https://creativecommons.org/licenses/by-nc-nd/4.0/

\section{LICENCE}

CC BY-NC-ND 4.0

\section{REPOSITORY RECORD}

Memon, Saim, Farukh Farukh, Philip C. Eames, and Vadim V. Silberschmidt. 2019. "A New Low-temperature Hermetic Composite Edge Seal for the Fabrication of Triple Vacuum Glazing”. figshare.

https://hdl.handle.net/2134/18537. 


\section{Accepted Manuscript}

A new low-temperature hermetic composite edge seal for the fabrication of triple vacuum glazing

Saim Memon, Farukh Farukh, Philip. C. Eames, Vadim V. Silberschmidt

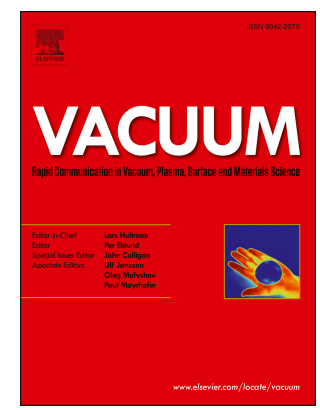

PII:

S0042-207X(15)00286-9

DOI:

10.1016/j.vacuum.2015.06.024

Reference: $\quad$ VAC 6728

To appear in: Vacuum

Received Date: 13 March 2015

Revised Date: 12 June 2015

Accepted Date: 13 June 2015

Please cite this article as: Memon S, Farukh F, Eames PC, Silberschmidt VV, A new low-temperature hermetic composite edge seal for the fabrication of triple vacuum glazing, Vaccum (2015), doi: 10.1016/ j.vacuum.2015.06.024.

This is a PDF file of an unedited manuscript that has been accepted for publication. As a service to our customers we are providing this early version of the manuscript. The manuscript will undergo copyediting, typesetting, and review of the resulting proof before it is published in its final form. Please note that during the production process errors may be discovered which could affect the content, and all legal disclaimers that apply to the journal pertain. 
A new low-temperature hermetic composite edge seal for the fabrication of triple vacuum glazing

Saim Memon ${ }^{1}$, Farukh Farukh ${ }^{2}$, Philip. C. Eames ${ }^{1}$, Vadim V. Silberschmidt ${ }^{2}$

${ }^{1}$ Centre for Renewable Energy Systems Technology (CREST), School of Electronic,

Electrical and Systems Engineering, Loughborough University, Loughborough, LE11 $3 T U, U K$.

${ }^{2}$ Mechanics of Advanced Materials, Wolfson School of Mechanical and Manufacturing Engineering, Loughborough University, Loughborough, LE11 3TU, UK

Corresponding Author: Saim Memon

Affiliation: Centre for Renewable Energy Systems Technology, School of Electronic, Electrical \& Systems Engineering, Loughborough University, Loughborough, LE11 3TU, UK.

Email: S.Memon@nescol.ac.uk; Tel: +44 (0) 1224612735

Address: School of Engineering, Science \& Technology, North East Scotland College, Altens Industrial Estate, Aberdeen, UK, AB12 3LE 


\section{Abstract}

High performance low-cost vacuum glazing is a key development in the move to more energy-efficient buildings. This study reports the results of experimental and theoretical investigations into the development of a new low-temperature (less than $200^{\circ} \mathrm{C}$ ) composite edge seal. A prototype triple vacuum glazing of dimensions $300 \mathrm{mmx} 300 \mathrm{~mm}$ was fabricated with a measured vacuum pressure of $4.8 \times 10^{-2} \mathrm{~Pa}$ achieved. A three-dimensional finite-element model for this prototype triple vacuum glazing with the composite edge seal was also developed. Centre-of-pane and total thermal transmittance values for this small prototype of the triple vacuum glazing were predicted to be $0.33 \mathrm{Wm}^{-2} \mathrm{~K}^{-1}$ and $1.05 \mathrm{Wm}^{-2} \mathrm{~K}^{-1}$, respectively. It was predicted using the developed model that the thermal performance could be improved by reducing the width of the composite edge seal and by the use of soft low-emissivity coatings on the glass surfaces. Detailed three-dimensional isothermal contour plots of the modelled triple vacuum glazing are presented.

Keywords: vacuum glazing, composite hermetic edge seal, finite-element modelling, thermal performance. 


\section{Introduction}

In buildings, where day-lighting and solar gains are advantageous, large window sizes are a desired feature to increase day-lighting and solar gains [1]. In order to increase the window size, without increasing the space-heating load, low heat loss glazing is required of which vacuum glazing is one option [2]. For large area vacuum glazing the use of tempered glass is advantageous which necessitates a method of lowtemperature edge sealing, this is due to the loss of glass temper at temperatures greater than $300^{\circ} \mathrm{C}$ [3]. A low temperature method of fabricating double vacuum glazing was first developed at the University of Ulster [4,5]. This method used indium or one of its alloys to seal the edges of the glass sheets hermetically at a temperature of less than $200^{\circ} \mathrm{C}$. The predicted, and experimentally determined, thermal transmittance of an indium sealed double vacuum glazing was reported to be less than $1 \mathrm{Wm}^{-2} \mathrm{~K}^{-1}$ for the central glazing area [6-8]. To reduce the heat loss to a level where the thermal transmittance of the central glazing area is less than $0.5 \mathrm{Wm}^{-2} \mathrm{~K}^{-1}$ [9], the concept of triple vacuum glazing was introduced [10]. This consists of three sheets of glass, a vacuum tight seal around the periphery of the three glass sheets, and two evacuated cavities at a pressure below $0.1 \mathrm{~Pa}$ to reduce heat transfer by gaseous conduction and convection to a negligible level. Radiative heat transfer can be reduced to a low level by using soft low-emittance coatings such as silver (Ag) on the surfaces of the glass sheets [4]. An array of stainless steel support pillars, typically $0.15 \mathrm{~mm}$ high and $0.3 \mathrm{~mm}$ diameter, maintain the separation of the three glass sheets. 
The scarcity and cost of indium are challenges in advancing indium-sealed vacuum glazing technology to the mass production level. The abundance of indium in the Earth's crust was estimated [11] to be about $0.05 \mathrm{ppm}$ for the continental and 0.072 ppm for the oceanic crust, respectively, which is much lower than the abundance of Sn, i.e. $2 \mathrm{ppm}$ in the earth's crust [12]. There thus exists a requirement to identify or develop alternative low-temperature edge sealing materials that do not suffer from these challenges prior to this technology being suitable for mass production.

A selection of different metals and alloys were assessed and tested prior to the successful development of a new low-temperature method for hermetically sealing the glass edges in a vacuum glazing. These included Sn wires (purity of $99.95 \%$ and 99.999\%), Sn63PB37, Sn90In10, Cerasolzer (type 297, 246, 224 and 186) and combinations of these alloys with an embedded annealed copper wire gasket. From laboratory experiments it was apparent that a good hermetic bond can be formed using several different materials but because of stresses developed during the fabrication process, the glass bends and stretches during heating and evacuation, leading to cracks in the seal area occurring when subject to the pressure difference between the vacuum cavity $(0.1 \mathrm{~Pa}$ or less) and atmosphere $(100,000 \mathrm{~Pa})[13]$. To increase the mechanical rigidity of the primary edge seal, a secondary edge seal (i.e. an adhesive such as araldite or J-B weld epoxy steel resin) was employed to provide increased bond strength and rigidity. After many experiments a clear understanding of the behaviour of Cerasolzer CS186 at a range of different temperatures was gained. This enabled a process to produce a composite glass edge seal suitable for fabrication of triple vacuum glazing to be developed, as illustrated schematically in Fig. 1. 
The primary edge seal material selected, Cerasolzer CS186, is a composite of $\mathrm{Sn}(56 \%), \mathrm{Pb}(39 \%), \mathrm{Zn}(3 \%), \mathrm{Sb}(1 \%)$ and $\mathrm{Al}-\mathrm{Ti}-\mathrm{Si}-\mathrm{Cu}(1 \%)$ alloys [14].This metal alloy composition was disclosed in the Japanese patent 20098/1968 [15] and is a commercial product of the Asahi Glass Co., Ltd $[16,17]$. The secondary edge seal material used is a steel reinforced epoxy known under the commercial trade name of J-B Weld epoxy steel resin. It is capable of sustaining constant temperatures of up to $260^{\circ} \mathrm{C}$ with a maximum temperature threshold of up to $316^{\circ} \mathrm{C}$ for 10 minutes [18].

A new stepped arrangement of the three glass sheets was developed, as shown in Fig. 1, which allows primary and secondary seals of $10 \mathrm{~mm}$ and $4 \mathrm{~mm}$ width to be used. . With such a wide edge seal, edge seal conduction and its influence on the thermal performance of the triple vacuum glazing are important in determining the performance of this new design for triple vacuum glazing. In the work presented in this paper, a three-dimensional finite-element model for the fabricated prototype of triple vacuum glazing with this edge seal design was developed using the measured composite edge seal thermal properties. This enabled the influence of wider edge seals on the predicted thermal performance to be investigated. The simulation results were compared with those reported for the thermal performance of triple vacuum glazing in the literature.

\section{Cerasolzer and Indium surface analysis}

The use of ultrasonic soldering an approach used previously for Indium sealed vacuum glazing [4] was initially found to be more challenging when forming a 
Cerasolzer with significant difficulty in maintaining the surface consistency and smoothness. After many trials, it was found that the best results were obtained with ultrasonic vibrations of approximately $25 \mathrm{kHz}$ and a temperature setting of $186^{\circ} \mathrm{C}$, this led to a contiguous mechanical bond being formed between the Cerasolzer and the glass surface. Due to the mechanical bond formed Cerasolzer was considered to be a suitable material for use in an edge seal for triple vacuum glazing. Samples with Indium and Cerasolzer ultrasonically soldered to the glass surfaces of two $1 \mathrm{~mm}$ thick slide cover slips, each of area $20 \mathrm{~mm}$ x $20 \mathrm{~mm}$, as illustrated in Fig.2. were produced. A DualBeam (FIB-SEM) microscope was used to comparatively analyse the surface micro-structure, smoothness and consistency of both the indium and Cerasolzer surfaces. This comparison with indium was made because it is a material successfully used for hermetically-sealing the edges of glass sheets in a vacuum glazing [4]. It can be seen that the Cerasolzer coated sample shown in Fig. 2a has a similar smooth appearance to an identically prepared sample using indium shown in Fig. 2b. The uniform surface obtained with these materials is a key feature for obtaining a viable vacuum tight edge seal.

An X-ray high-resolution CT (Computed Tomography) system was used to analyse the homogeneity of the indium and the Cerasolzer layers when used to bond two $4 \mathrm{~mm}$ thick k-glass samples of area $10 \mathrm{~mm}$ x $10 \mathrm{~mm}$ together. Views through the cross-section at the interface between the glass and indium and glass and Cerasolzer are presented in Fig. 3. It can be seen from Fig. 3a that the glass- indium bond has several micro pinholes or voids with air trapped inside, which may affect the hermeticity of the edge seal when used for vacuum glazing. This phenomenon was also detected and 
discussed by Zhao et al [19]. It can be seen from Fig. 3b that there are fewer, smaller micro pin holes (with air trapped inside) for the Cerasolzer-glass bond sample than in the indium-glass bond shown in Fig. 3a. It was reported by Griffiths et al [4], Eames [9] and Zhao et al [6] that an indium-glass sealed sample should not be overheated since this leads to the indium flowing excessively and that a secondary adhesive edge seal is required to avoid moisture ingress and seal degradation. Due to the apparent similarities between Cerasolzer and Indium glass bonds it is probable that vacuum glazing with a Cerasolzer seal will require a secondary seal also.

\section{Glass-Cerasolzer bond}

To assess the continuity of the glass-Cerasolzer bond, a $10 \mathrm{~mm}$ wide joint between two $4 \mathrm{~mm}$ thick k-glass sheets (each of area $20 \mathrm{~mm}$ x $20 \mathrm{~mm}$ ) was made using an ultrasonic soldering iron at a set temperature of $186^{\circ} \mathrm{C}$ to coat half of one surface of both glass sheets with Cerasolzer and then butting the coated surfaces together and heating in an oven set to a temperature of $200^{\circ} \mathrm{C}$. The front side of the Cerasolzer joint at the interface between the glass and Cerasolzer was examined using DualBeam (FIBSEM) microscope shown in Fig. 4.The front side of the sample shows the interface of the Cerasolzer with the two glass surfaces. No cracks are observable in the interface. When the glass and Cerasolzer are heated the Cerasolzer expands more than the glass, it then contracts more when cooled due to the mismatch between the thermal expansion of glass, i.e. $8 \times 10^{-6} /{ }^{\circ} \mathrm{C}[20]$, and Cerasolzer alloy, i.e. $23.5 \times 10^{-6} /{ }^{\circ} \mathrm{C}$ [14]. It was observed that the cooling process had introduced stresses in the bonded area which could be minimised by slowly cooling the sample down to ambient temperature. The quantity 
and uniformity of the Cerasolzer deposited on the glass surface is an important factor in achieving a contiguous edge seal. This illustrated that Cerasolzer can bond glass to glass and has the potential to achieve a bond.

\section{Composite edge seal interface analysis}

Initial experiments, as outlined in Memon and Eames [13], indicated that the proposed Cerasolzer edge seal is sensitive to glass bending due to the pressure difference between the vacuum cavity (0.1Pa or less) and atmosphere (100,000Pa). J-B Weld epoxy steel resin was used to form a secondary seal to increase the mechanical rigidity of the primary seal intended for triple vacuum glazing. J-B Weld was selected due to its mechanical strength and hardness, which was expected to keep the three glass sheets rigidly located with respect to each other and protect the glazing geometry. a $10 \mathrm{~mm}$ wide joint between two $4 \mathrm{~mm}$ thick k-glass sheets (each of area $20 \mathrm{~mm}$ x 20 $\mathrm{mm}$ ) was made using an ultrasonic soldering iron at a set temperature of $186^{\circ} \mathrm{C}$ to coat half of one surface of both glass sheets with Cerasolzer and then butting the coated surfaces together and heating in an oven set to a temperature of $200^{\circ} \mathrm{C}$.

To investigate the composite edge seal, two samples each having a $10 \mathrm{~mm}$ wide Cerasolzer lap joint (which was made in a similar way to the previous sample discussed in section 3) between two $4 \mathrm{~mm}$ thick k-glass sheets were fabricated, six support pillars (height of $0.15 \mathrm{~mm}$ and $0.3 \mathrm{~mm}$ in diameter) were used to space the glass sheets apart to achieve an approximate $0.15 \mathrm{~mm}$ thick bond similar to that required for a vacuum glazing. J-B weld was then used to coat the external surface of the bond shown in Fig 5. 
The composite edge bond at the glass edge was analysed using a DualBeam (FIB-SEM) microscope, with images obtained shown in Fig. 5. Fig 5a shows two glass pieces bonded with Cerasolzer and J-B Weld on the one side edge of the sample, while Fig. $5 b$ shows a similar bond with cracks and pin holes in the J-B weld epoxy. This occurs when the mixture of steel-reinforced paste and hardener are not at the correct weight fraction, this was a feature that should be avoided when fabricating triple vacuum glazing to prevent moisture ingress.

\section{Fabrication process for triple vacuum glazing}

A design illustrated schematically in Fig. 6, to join three sheets of glass hermetically was employed for the fabrication of a triple vacuum glazing, the seal consists of a primary edge seal, a $10 \mathrm{~mm}$-wide layer of Cerasolzer and a secondary edge seal, a 4 mm-wide layer of J-B Weld epoxy steel resin. The reason for using different sizes of glass sheets was to allow application of the secondary edge seal uniformly around the periphery of the triple vacuum glazing to support and protect the primary edge seal. There is a trade-off between the width of the edge seal (10mm chosen to increase the durability and guarantee vacuum integrity) and the thermal performance of vacuum glazing due to edge conduction (i.e. an increase in heat transfer through the edge sealing area). It is anticipated that with refinement the total width of the combined edge seal could be reduced from $14 \mathrm{~mm}$ down to $8 \mathrm{~mm}$. The fabrication process was implemented as follows: 
1) $4 \mathrm{~mm}$-thick K-glass sheets of size $284 \mathrm{~mm}$ x $284 \mathrm{~mm}$ (upper sheet), $292 \mathrm{~mm}$ x $292 \mathrm{~mm}$ (middle sheet) and $300 \mathrm{~mm}$ x $300 \mathrm{~mm}$ (bottom sheet) were cut to size. $4 \mathrm{~mm}$ diameter holes were drilled for the evacuation of the two cavities between the three glass sheets, located at $75 \mathrm{~mm}$ from two edges of the smaller and middle glass sheets.

2) The sheets of glass were cleaned with water, acetone and isopropanol and followed by an initial bake-out at $120^{\circ} \mathrm{C}$ in an oven.

3) A $10 \mathrm{~mm}$-wide layer of Cerasolzer alloy was ultrasonically soldered around the periphery of the upper and lower glass sheets on the tin-oxide coated side. In addition, a similar $10 \mathrm{~mm}$ layer was soldered on both surfaces of the middle sheet and formed in to the arrangement shown in Fig. 7. The uniformity of the soldered edge seal was considered very important, and the level of uniformity achieved is illustrated in the Fig. 7. A glass square for sealing the pump-out hole was prepared from a slide cover slip by cutting it to dimensions of $18 \mathrm{~mm} \times 18 \mathrm{~mm}$ and ultrasonically soldering its surface with Cerasolzer alloy.

4) Stainless-steel support pillars were placed at a spacing of $24 \mathrm{~mm}$ in a regular square array on the middle and lower glass sheets. The middle sheet was placed on the pillars of the lower glass sheet and then the upper glass sheet was placed on top of the support pillars on the middle glass sheet.

5) The sample was heated to $186^{\circ} \mathrm{C}$ for up to 2 hours in the oven to join the three sheets of glass together. 
6) The assembly was allowed to cool down to ambient temperature of around $21^{\circ} \mathrm{C}$. The epoxy J-B Weld was used to form the secondary seal.

7) The sample was placed on the hot plate and heated to $50^{\circ} \mathrm{C}$, at which point the cavity of the sample was evacuated using a vacuum cup pump-out assembly.

8) During evacuation, after approximately 6 hours, the pump-out hole was sealed by heating the glass square using the cartridge heater located inside the vacuum cup pump-out assembly.

\section{Experimental results for triple vacuum glazing}

A triple vacuum glazing of dimensions $300 \mathrm{~mm}$ x $300 \mathrm{~mm}$ as shown in the Fig.8 was fabricated after four trials, in which the process was refined. A viable fabrication process was achieved during these experiments with successful samples produced subsequently. The pump-out hole of the triple vacuum glazing was sealed with Cerasolzer CS186 alloy during evacuation. In initial experiments, samples were reevacuated with repeated pump-out hole sealing to assess the sealing properties and the pump-out hole sealing characteristics. It was found that similar behaviour was obtained for multiple evacuation cycles with stress patterns due to internal compressive stress and external tensile stress across the support pillars observable. This indicates that a vacuum-tight seal was being achieved. Based on the experiments performed, the process was revised so that: 
1) During evacuation the sample was heated to not more than $80^{\circ} \mathrm{C}$ on the hot plate, this was because the glass bends due to temperature induced stresses and higher temperatures can fracture the glass, weaken or destroy the primary edge seal.

2) If soldering of the Cerasolzer around the periphery of the glass surfaces is highly uniform an effective seal can be found without recourse to including a wire gasket.

For these experiments a dry type turbo-molecular pump with backing (diaphragm) pump was used that had an absolute achievable vacuum pressure of $4.35 \times 10^{-5} \mathrm{~Pa}$. A pressure gauge was used to measure the vacuum pressure near the vacuum cup in order to determine the approximate pressure within the vacuum glazing cavity. The pressure gauge was connected to a PDR 900 transducer to provide digital output of pressure in $\mathrm{Pa}$; this transducer was interfaced with a computer for monitoring purposes. The achieved vacuum pressure in the triple vacuum glazing was $4.8 \times 10^{-2} \mathrm{~Pa}$. Temperature/pressure profiles for the evacuation and heating process were recorded and are presented in Fig. 9. It was observed that a lower vacuum pressure was obtained when increasing the sample temperature using the hot plate. However, a high level of internal compressive stresses and external tensile stresses were observed for sample temperatures above $50^{\circ} \mathrm{C}$ that could cause fracture of the glass; glass bending and expansion were also observed to increase with increasing hot plate temperature. A limit on the hot plate surface temperature was thus set at $50^{\circ} \mathrm{C}$ during evacuation and pumpout sealing to minimise this effect. Detailed studies of stresses in vacuum glazing are reported elsewhere [20, 21]. 


\section{Thermal performance prediction for triple vacuum glazing}

\subsection{Finite-Element Modelling Approach}

To simulate the heat transfer process and to predict the thermal performance of the fabricated triple vacuum glazing, a three-dimensional finite-element model was developed using the commercial software package MSC.Marc. Due to symmetry conditions, and to reduce the computational effort required, only one quarter (150 mm x $150 \mathrm{~mm}$ ) of the fabricated triple vacuum glazing of dimensions $300 \mathrm{~mm}$ x $300 \mathrm{~mm}$ was simulated. The developed model was designed to represent the fabricated triple vacuum glazing. The model was implemented using eight-node isoparametric elements (type 43 in MSC Marc), with a total of 170455 elements and 201660 nodes used to model a quarter of the fabricated triple vacuum glazing as shown in Fig. 10. The vacuum cavity was modelled as a material with thermal conductivity considered near to zero. Heat transfer by long-wave radiation between the three internal glass surfaces coated with low-emissivity tin-oxide coatings was incorporated by employing a $6 \mu \mathrm{m}$ layer on the inner surface of the glass sheet with the emissivity of tin-oxide. In the three-dimensional finite-element model, the support pillars were incorporated and modelled directly; similar to the modelling approach used by Fang et al. [8] and Zhao et al. [6]. The cylindrical pillars of radius $r$ employed in the fabricated triple vacuum glazing were represented by the same number of pillars with the same cross-sectional areas in the developed finite-element model. For simplicity, the cylindrical pillars were approximated by a square cross-section in the model with side length $1.78 r$, as both pillar shapes with the same cross sectional area will conduct similar amounts of heat 
under the same boundary conditions $[20,22]$. A graded mesh with a higher number of elements in the pillars was employed to achieve adequate representation of the heat transfer. An example of the finite-element mesh employed is shown in Fig. 10. A series of convergence tests were performed to ensure that the density of the elements used was sufficient to predict the thermal performance with an accuracy of more than $95 \%$. The material properties and parameters of the simulated triple vacuum glazing are listed in Table 1.

For the simulations the indoor warm-side (Ti) and outdoor cold-side (To) internal and external surface air temperatures were set to be at $21.1^{\circ} \mathrm{C}$ and $-17.8^{\circ} \mathrm{C}$ [5], respectively, in line with ASTM-specified test conditions for glazings in winter conditions [26]. The internal and external surface heat transfer coefficients were set to $8.3 \mathrm{Wm}^{-2} \mathrm{~K}^{-1}$ and $30 \mathrm{Wm}^{-2} \mathrm{~K}^{-1}$, respectively [27]. The glass surface to surface thermal transmittance of the total glazing $\left(\mathrm{U}_{\text {total }}\right)$ and the centre-of-pane glazing $\left(\mathrm{U}_{\text {centre }}\right)$ are defined by:

$$
\begin{aligned}
& U_{\text {centre }}=\frac{1}{\operatorname{Rsi}_{\text {centre }}+\frac{A_{\text {centre }}\left(\mathrm{Ti}_{\text {centre }}+\mathrm{To}_{\text {centre }}\right)}{\mathrm{Q}_{\text {centre }}}+\mathrm{Rso}_{\text {centre }}}, \\
& \mathrm{U}_{\text {total }}=\frac{1}{\mathrm{Rsi}_{\text {total }}+\frac{\mathrm{A}_{\text {total }}\left(\mathrm{Ti}_{\text {total }}+\mathrm{To}_{\text {total }}\right)}{\mathrm{Q}_{\text {total }}}+\mathrm{Rso}_{\text {total }}},
\end{aligned}
$$

Where, Rsi and Rso are the indoor and outdoor glazing surface thermal resistances, in $\mathrm{m}^{2} \mathrm{KW}^{-1} . \mathrm{A}_{\text {centre }}\left(\mathrm{m}^{2}\right)$ is the total glazing area minus the edge areas of glass [7]. 


\subsection{Predicted Thermal Performance}

Centre-of-pane and total thermal transmittance values for a triple vacuum glazing of dimensions $300 \mathrm{~mm} \times 300 \mathrm{~mm}$ were predicted to be $0.33 \mathrm{Wm}^{-2} \mathrm{~K}^{-1}$ and 1.05 $\mathrm{Wm}^{-2} \mathrm{~K}^{-1}$, respectively. Manz et al. [28] predicted a centre-of-pane thermal transmittance value of less than $0.2 \mathrm{Wm}^{-2} \mathrm{~K}^{-1}$, for a triple vacuum glazing made with 6 $\mathrm{mm}, 4 \mathrm{~mm}$ and $6 \mathrm{~mm}$ thick glass sheets and four low-emittance coatings with emittance of 0.03. Comparing this with the current simulated centre-of-pane thermal transmittance, the increase of $0.13 \mathrm{Wm}^{-2} \mathrm{~K}^{-1}$ was due to the use of tin-oxide coatings with an emittance of 0.15 on three internal surfaces and the use of three $4 \mathrm{~mm}$-thick glass sheets. The parameters used in the simulations were based on the fabricated sample design and taken from the datasheets referenced in Table 1. Fang et al. [29] predicted the centre-of-pane and total thermal transmittance values to be $0.26 \mathrm{Wm}^{-2} \mathrm{~K}^{-1}$ and $0.65 \mathrm{Wm}^{-2} \mathrm{~K}^{-1}$, respectively. For a triple vacuum glazing of dimensions $500 \mathrm{~mm} \mathrm{x}$ $500 \mathrm{~mm}$ with a $6 \mathrm{~mm}$-wide indium edge seal and four low-emittance coatings with emittance of 0.03 on $4 \mathrm{~mm}$-thick glass sheets. Comparing to the current simulated results, the increases of $0.07 \mathrm{Wm}^{-2} \mathrm{~K}^{-1}$ and $0.4 \mathrm{Wm}^{-2} \mathrm{~K}^{-1}$ were caused by the $10 \mathrm{~mm}$-wide primary seal and $4 \mathrm{~mm}$-wide secondary seal around the periphery of the edge area, the use of tin-oxide coatings on three internal surfaces of the glass sheets and the smaller size of the fabricated sample, i.e. $300 \mathrm{~mm} \times 300 \mathrm{~mm}$.

It was predicted [29-30] that the glazing size due to edge effects influences the total thermal transmittance; for example, the value of total thermal transmittance of a triple vacuum glazing of area $500 \mathrm{~mm} \times 500 \mathrm{~mm}$ was predicted to be $38 \%$ greater than 
that of a $1000 \mathrm{~mm} \times 1000 \mathrm{~mm}$ glazed area. In these simulations the thermal transmittance of the triple vacuum glazing dimensions of $300 \mathrm{~mm} \times 300 \mathrm{~mm}$ was predicted to be $61.9 \%$ greater than the predictions of Fang et al. [29] model of the 500 $\mathrm{mm} \times 500 \mathrm{~mm}$ area. It must be noted that the sample size, surface emissivities and the seal materials' properties all influence the predictions of thermal transmittance [30], if these factors are allowed for then model predictions are in good agreement.

The predicted isotherms of the modelled triple vacuum glazing for the cold surface, middle glass surfaces and warm surface are presented in Figs. 11- 14. The heat transfer mechanisms modelled included: (i) the heat flux from the indoor (warm) side to the indoor glazing surface; (ii) radiation between two inner glass surfaces within the two vacuum gaps; (iii) conduction through the support pillars and the edge seal, and (iv) the heat flux from the outdoor (cold) surface of the glass to the outdoor side. The mean glass surface temperatures were predicted to be $-12.55^{\circ} \mathrm{C}$ and $6.71^{\circ} \mathrm{C}$ for the cold and warm sides of the total glazing area. The mean surface temperatures for the centre of glazing area were predicted to be $16.43^{\circ} \mathrm{C}$ and $-16.60^{\circ} \mathrm{C}$ for the cold and warm sides, respectively.

Fig. 11 presents the predicted isotherms of the warm (indoor side) glass surface showing the temperature variations from the edge area towards the central area and around the support pillars in the central glazing area for the simulated triple vacuum glazing. The temperature difference between the heat conduction through the support pillars and radiative heat flow in the central vacuum area is predicted to be $0.47^{\circ} \mathrm{C}$. 
Fig. 12 shows the predicted isotherms for the middle-glass surface facing the warm side in terms of the temperature variations from the edge area towards the central area of the simulated triple vacuum glazing. It can be seen from the Fig. 12 that the heat flow through the support pillars is greater than that through the vacuum area. The influence of the $10 \mathrm{~mm}$-wide layer of the primary and $4 \mathrm{~mm}$-wide layer of the secondary edge seal, on the predicted temperatures is demonstrated in Fig. 12.

The predicted isotherms for the surface facing the cold side of the middle glass sheet are given in Fig. 13. The variation in temperature at the pillar location is due to higher heat flow through them than in the vacuum area.

Fig. 14 presents the predicted isotherms for the cold (outdoor side) glass surface. The temperature variations due to the edge seal and the support pillar array can be clearly seen. As seen in Fig. 14, the temperature difference due to heat conduction through the support pillars and radiative heat flow through the central vacuum area is predicted to be $0.4^{\circ} \mathrm{C}$.

The heat dissipating temperature profiles along lines $\mathrm{AA}$ and $\mathrm{BB}$, extending from the edge to the centre-of-pane, of one quarter $(150 \mathrm{~mm} \times 150 \mathrm{~mm})$ of the fabricated triple vacuum glazing of dimensions $300 \mathrm{~mm}$ x $300 \mathrm{~mm}$ were simulated and presented in Fig. 15. Lines AA and BB are shown on Fig. 11 and Fig. 14. It shows the temperature difference between the warm (indoor side) glass surface and cold (outdoor side) glass surface under ASTM boundary conditions. The predicted temperature variations on the cold side surface are smaller than on the warm side. Because of the 
stepped arrangement of the three glass sheets that allows the use of $10 \mathrm{~mm}$ and $4 \mathrm{~mm}$ wide layers of primary and secondary seal. Significant heat dissipation can be seen at the edge-seal sightline. And subsequent edge effects that extend up to distances of 84 $\mathrm{mm}$ and $54 \mathrm{~mm}$ from the edge to the centre-of-pane on the warm and cold surfaces of the fabricated triple vacuum glazing respectively. Comparing the temperature profiles along the line $\mathrm{AA}$ with the line $\mathrm{BB}$ on the warm and cold side surfaces, it can be seen that the temperature variations on the line $\mathrm{BB}$ is slightly closer to the temperature profiles on the line AA due to edge effects as also discussed in [30]. It can be reduced by decreasing the width of the edge seal and/or adding an insulating layer [31] that extends past the edge-seal sightline.

\section{Conclusions}

In this study, a new method of fabricating a triple vacuum glazing based on a low-temperature (less than $200^{\circ} \mathrm{C}$ ) composite edge sealing process was investigated experimentally and theoretically. Due to the mechanical bond formed after many trials Cerasolzer type CS186 was considered to be a suitable material for use in an edge seal for triple vacuum glazing. The micro-structure of Cerasolzer was investigated using a DualBeam (FIB-SEM) and it was proved to be smooth and consistent compared to a likewise low-temperature based indium edge seal. The uniform surface obtained with these materials is a key feature for obtaining a viable mechanical bond. When examined with an X-ray high-resolution CT (Computed Tomography) system the homogeneity of the indium and the Cerasolzer layers formed between two glass sheets was achieved. Experiments indicate that the Cerasolzer type CS186 edge seal formed is sensitive to 
glass bending due to the pressure difference between the vacuum cavity and atmosphere. It was experimentally demonstrated that including a secondary seal of J-B Weld epoxy provided sufficient mechanical rigidity to maintain the primary seal. The fabrication process proved to be successful in achieving a vacuum pressure of $4.8 \times 10^{-2}$ $\mathrm{Pa}$ in the two gaps between the three glass sheets. Due to the width of the composite edge seal heat transfer in this areas will have a significant influence on the thermal performance of the triple vacuum glazing developed to investigate this effect a threedimensional finite-element model for this prototype of triple vacuum glazing was also developed. In which an influence of wider edge seal on the thermal performance was investigated. Centre-of-pane and total thermal transmittance values in the model of a composite edge sealed triple vacuum glazing with dimensions of $300 \mathrm{~mm}$ x $300 \mathrm{~mm}$ were predicted to be $0.33 \mathrm{Wm}^{-2} \mathrm{~K}^{-1}$ and $1.05 \mathrm{Wm}^{-2} \mathrm{~K}^{-1}$. Improvements in thermal performance can be achieved by reducing the total width of the edge seal from $14 \mathrm{~mm}$ to $8 \mathrm{~mm}$ and by the use of better performing soft low-emissivity coatings on the glass surfaces.

\section{Acknowledgement}

This work was supported by the Engineering and Physical Sciences Research Council (EPSRC) of the UK (EP/G000387/1) as a contribution to the Work Package 3.4 of the CALEBRE (Consumer-Appealing Low Energy Technologies for Building Retrofitting) project. 


\section{References}

[1] C. E. Ochoa, M. B. C. Aries, E. J. Van Leonen, J. L. M. Hensen. Considerations on design optimization criteria for windows providing low energy consumption and high visual comfort. Applied Energy 2012; 95: 238-245.

[2] S. Memon, P. C. Eames, Heat load and solar gain prediction for solid wall dwellings retrofitted with triple vacuum glazing for selected window to wall area ratios, World Renewable Energy Forum, WREF 2012, Including World Renewable Energy Congress XII and Colorado Renewable Energy Society (CRES) Annual Conference. ASES publishing 2012;6:4636-4643.

[3] D. R. Uhlmann, N. J. Kreidl. 1980. Glass Science and Technology: Elasticity and Strength in glasses, Vol 5, Academic Press Inc, London, 1980.

[4] P.W. Griffiths, M. D. Leo, P. Cartwright, P. C. Eames, P. Yianoulis, G. Leftheriotis, B. Norton, Fabrication of evacuated glazing at low temperature. Solar Energy 1998; 63: 243-249.

[5] P. W. Griffiths, B. Norton, P. C. Eames, S. N. G. Lo. Detailed simulation of heat transfer across planar evacuated glazing. Building Research \& Information 1996, 24:3, 141-147. 
[6] J. F. Zhao, P. C. Eames, T. J. Hyde, Y. Fang, J. Wang. A modified pump-out technique used for fabrication of low temperature metal sealed vacuum glazing. Solar Energy 2007; 81: 1072-1077.

[7] Y. Fang, T. J, P. C. Eames, B, Norton. Effect of glass thickness on the thermal performance of evacuated glazing. Solar Energy 2007; 81: 395-404.

[8] Y. Fang, P. C. Eames, B, Norton, T. J. Hyde. Experimental validation of a numerical model for a heat transfer in vacuum glazing. Solar Energy 2006; 93:564-577.

[9] P. C. Eames. Vacuum glazing: Current performance and future prospects. Vacuum 2008; 82: 717-722.

[10] W. Wuethrich, Heat transmission reducing closure element, European Patent No. $1529921,2005$.

[11] U. S. Schampera, Herzig, P. M. Indium: Geology, Mineralogy and Economics. Springer, 2002.

[12] L. V. Maness, Predicting Indium and Tellurium availability. IEEE Photovoltaic Specialists Conference; 2010, p. 560-613. 
[13] S. Memon, P. C. Eames, An investigation on edge sealing materials for the fabrication of vacuum glazing, Oral presentation, $3^{\text {rd }}$ School of Electrical, Electronic and Systems Engineering (EESE) Research conference, Loughborough University, 2013.

[14] Senju Metal Industry Co., Ltd. Cerasolzer \#C186-material safety data sheet. Senju Metal Industry Co. Ltd., Tokyo, 2013.

[15] H. Yamamoto, R. Ohmuro, Imaging device utilizing solid-state image sensors combined with a beam-splitting prism, US Patent publication No. 4,916,529, Japan, 1990.

[16] Asahi Glass Co., Ltd., Cerasolzer New Metal Solder for Glass and Ceramics, 1991.

[17] MBR Electronics GmbH, Cerasolzer product information. [Viewed on 26/07/13] Available from <http://cerasolzer.com/cerasolzer/basic_info_gb.html>

[18] J-B Weld, J-B Weld adhesive resign and hardener. [Viewed on 26/07/2013] <http://www.jb-weld.co.uk/technical-data-sheets>

[19] J. F. Zhao, P. Eames, T. Hyde, Y. Fang, J, Wang. A new type of In/Cu/In seal for vacuum glazing. Renewable Energy in Maritime Island Climates Conference Dublin; 2006, p. 5 . 
[20] J. Wang, P.C. Eames, J.F. Zhao, T. Hyde, Y. Fang. Stresses in vacuum glazing at low temperature. Solar Energy Materials \& Solar Cells 2007; 91: 293-303.

[21] A. C. Fischer-Cripps, R. E. Collins, G. M. Turner, E. Bezzel, Stresses and fracture probability in evacuated glazing. Build. Environ 1995; 30: 41-59.

[22] Holman, J. P. Heat Transfer, SI Metric Edition, McGraw-Hill, New York, 1989.

[23] BS 6993, Thermal and radiometric properties of glazing-Part 1 Method for calculation of the steady state U-value (thermal transmittance), 1989.

[24] Eagle Steel, 304 stainless steel_MQ304A/ 12674 material properties. [Viewed on 11/06/13) Available from

<http://www.eaglesteel.com/download/techdocs/304_Stainless_Steel.pdf>

[25] S. Memon. Design, Fabrication and Performance Analysis of Vacuum Glazing Units Fabricated with Low and High Temperature Hermetic Glass Edge Sealing Materials. PhD Thesis. Loughborough University: UK, 2013.

[26] ASTM. Standard procedures for determining the steady state thermal transmittance of fenestration systems, ASTM Standard E 1423-91, in: 1994 Annual Book of ASTM Standard 04.07, American Society of Testing and Materials; 1991, p. 1160-1165. 
[27] Y. Fang, Y, T. J. Hyde, N. Hewitt, P. C. Eames, B. Norton Comparison of vacuum glazing thermal performance predicted using two and three dimensional models and their experimental validation. Solar Energy Materials \& Solar Cells 2009; 93: 14921498.

[28] H. Manz, S. Brunner, L. Wullschleger, Triple vacuum glazing: Heat transfer and basic mechanical design constraints, Solar Energy 2006; 80: 1632-1642.

[29] Y. Fang, T. J. Hyde, N. Hewitt. Predicted thermal performance of triple vacuum glazing. Solar Energy 2010; 84: 2132-2139.

[30] P. W. Griffiths, P. C. Eames, T. J. Hyde, Y. Fang, B. Norton, Experimental characterization and detailed performance prediction of a vacuum glazing system fabricated with a low temperature metal edge seal, using a validated computer model. Journal of Solar Energy Engineering, ASME 2006; 128: 199-203.

[31] T. M. Simko, R. E. Collins, F. A. Beck, D. Arasteh. Edge Conduction in vacuum Glazing. Proceedings of Thermal Performance of the Exterior Envelopes of Buildings VI, Florida, 1995. 


\section{Figure Captions}

Figure 1: A schematic diagram of a triple vacuum glazing showing the primary edge seal made of Cerasolzer CS186 alloy and a secondary edge seal of J-B weld epoxy steel resin.

Figure 2: Scanning electron microscopy image of two $20 \mathrm{~mm}$ x $20 \mathrm{~mm}$ x $1 \mathrm{~mm}$ slide cover slips with indium and Cerasolzer CS186 ultrasonically soldered on to the surface magnified at 5000x: (a) Cerasolzer alloy sample and (b) indium sample.

Figure 3: X-ray high-resolution CT cross-sectional view at the interface of the glass-indium bond (a) and the glass-Cerasolzer bond (b).

Figure 4: Scanning electron micrograph of glass-to-Cerasolzer bond's front surface showing no cracks in the bond.

Figure 5: Scanning electron micrographs of the composite edge seal made with two K- glass pieces separated by 6 support pillars (a) showing the composite edge seal of the sample and (b) a sample showing pin holes with cracks in the secondary epoxy seal.

Figure 6: The three-stage composite-edge-sealing design process for the fabrication of a triple vacuum glazing.

Figure 7: Illustration of the uniformity required in the ultrasonically soldered primary edge seal for the fabrication of a triple vacuum glazing.

Figure 8: A fabricated triple vacuum glazing of dimensions $300 \mathrm{~mm}$ x $300 \mathrm{~mm}$ with composite edge seal.

Figure 9: Typical temperature/pressure profiles for evacuation and heating of triple vacuum glazing sample.

Figure 10: Finite-element mesh of one quarter $(150 \mathrm{~mm}$ x $150 \mathrm{~mm})$ of the triple vacuum glazing. 
Figure 11: Predicted isotherms on the warm (indoor side) glass surface showing (A) the temperature variations from the edge area towards the central area and (B) the temperature variations around the centre-of-pane support pillar area for the simulated triple vacuum glazing.

Figure 12: Predicted isotherms for the middle-glass surface facing the warm side for the simulated triple vacuum glazing.

Figure 13: Predicted isotherms for the middle glass surface facing the cold side for the simulated triple vacuum glazing.

Figure 14: Predicted isotherms on the cold (outdoor side) glass surface showing (A) the temperature variations from the edge area towards the central glazing area and (B) the temperature variations around support pillars on the central glazing area of the simulated triple vacuum glazing.

Figure 15: The heat dissipating temperature profiles along lines $\mathrm{AA}$ and $\mathrm{BB}$, extending from the edge to the centre-of-pane, of one quarter $(150 \mathrm{~mm} \times 150 \mathrm{~mm})$ of the fabricated triple vacuum glazing of dimensions $300 \mathrm{~mm}$ x $300 \mathrm{~mm}$ under ASTM boundary conditions. 


\section{Table Captions}

Table 1: Parameters and material properties of the components used in the finite-element modelling of the composite edge sealed triple vacuum glazing. 
Table 1

\begin{tabular}{|c|c|c|}
\hline Parameter & Description & Value/Type \\
\hline \multirow{3}{*}{ Triple vacuum glazing dimensions } & Top glass sheet & $284 \mathrm{~mm}$ x $284 \mathrm{~mm}$ x $4 \mathrm{~mm}$ \\
\hline & Middle glass sheet & $292 \mathrm{~mm}$ x $292 \mathrm{~mm}$ x $4 \mathrm{~mm}$ \\
\hline & Bottom glass sheet & $300 \mathrm{~mm} \times 300 \mathrm{~mm} \times 4 \mathrm{~mm}$ \\
\hline Glass sheet & Thermal conductivity & $1 \mathrm{Wm}^{-1} \mathrm{~K}^{-1}[22]$ \\
\hline Emittance & Three surfaces (Hard coating) & $0.15 /$ tin-oxide \\
\hline \multirow[t]{3}{*}{ Primary edge seal } & Material & Cerasolzer CS186 \\
\hline & Width & $10 \mathrm{~mm}$ \\
\hline & Thermal conductivity & $46.49 \mathrm{Wm}^{-1} \mathrm{~K}^{-1} *$ \\
\hline \multirow[t]{3}{*}{ Secondary edge seal } & Epoxy steel resin & J-B Weld \\
\hline & Width & $\begin{array}{l}4 \mathrm{~mm} \text { (In the model } 8.3 \mathrm{~mm}^{2} \\
\text { equivalent square was incorporated) }\end{array}$ \\
\hline & Thermal conductivity & $7.47 \mathrm{Wm}^{-1} \mathrm{~K}^{-1} *$ \\
\hline \multirow[t]{5}{*}{ Support pillar } & Material & Stainless steel 304 \\
\hline & Diameter & $0.3 \mathrm{~mm}$ \\
\hline & Height & $0.15 \mathrm{~mm}$ \\
\hline & Pillar separation & $24 \mathrm{~mm}$ \\
\hline & Thermal conductivity & $16.2 \mathrm{Wm}^{-1} \mathrm{~K}^{-1}[23]$ \\
\hline
\end{tabular}




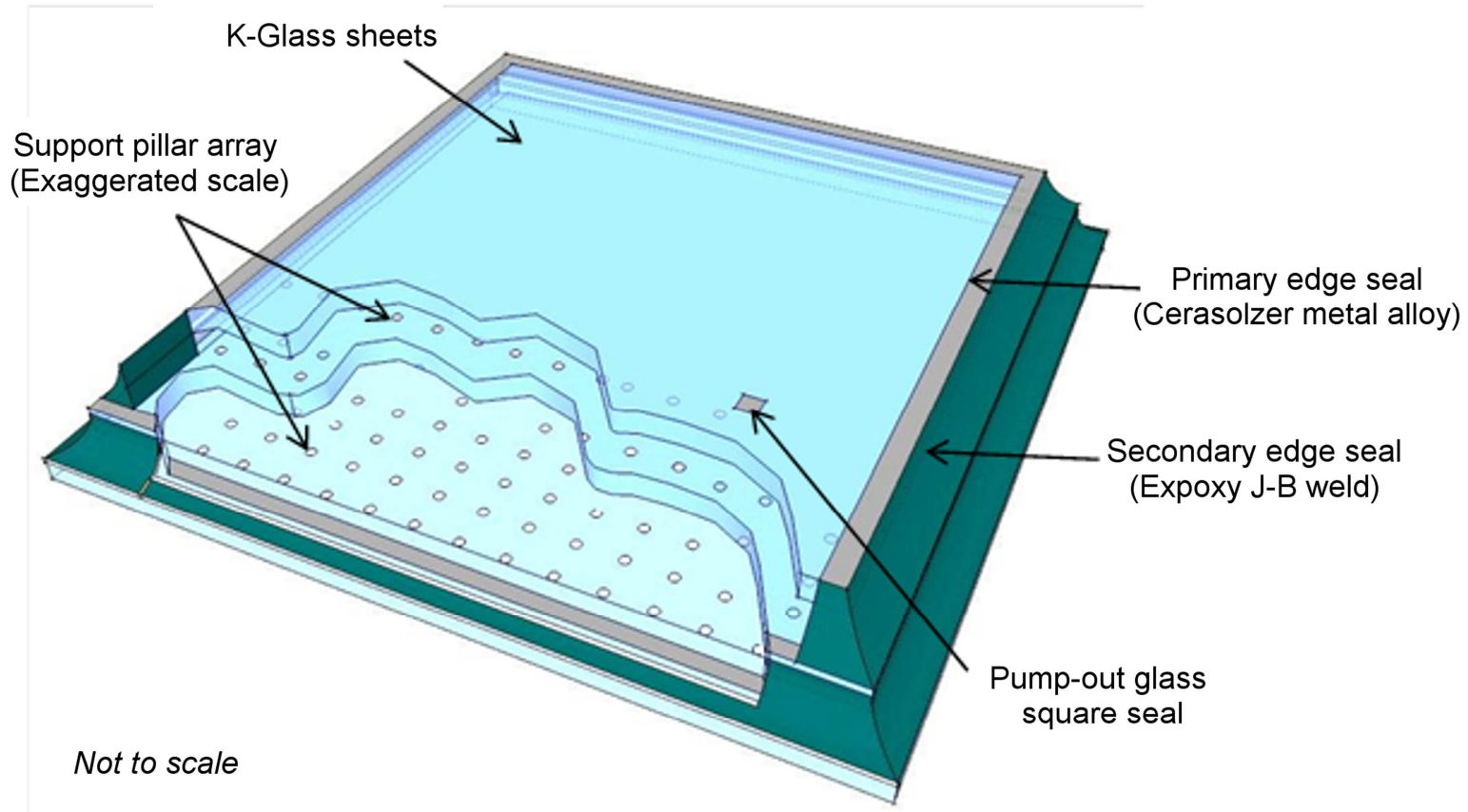




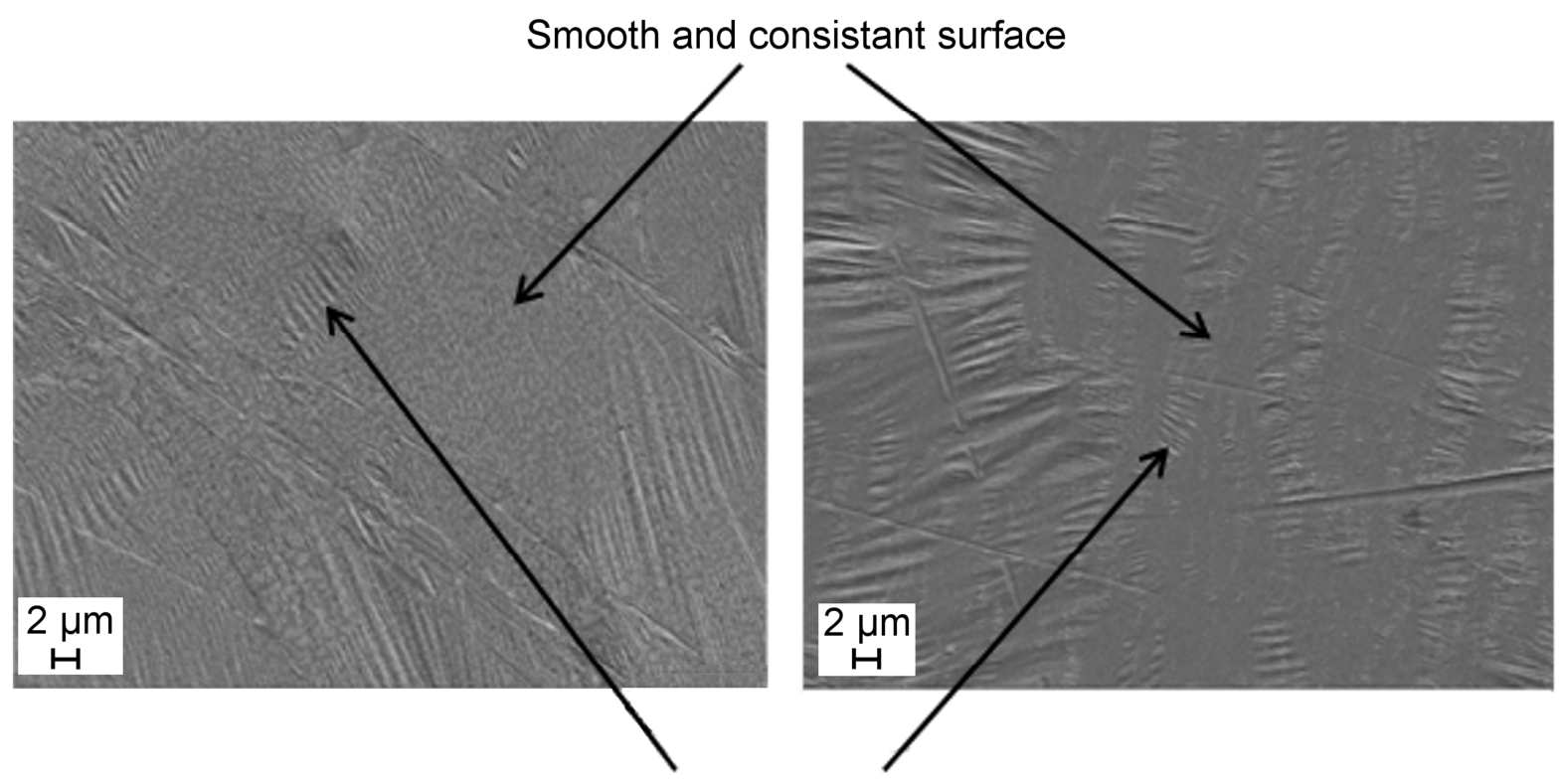

Lines of ultrasonic (high frequency) movements of the tip of soldering iron 
Pinhole with air trapped inside

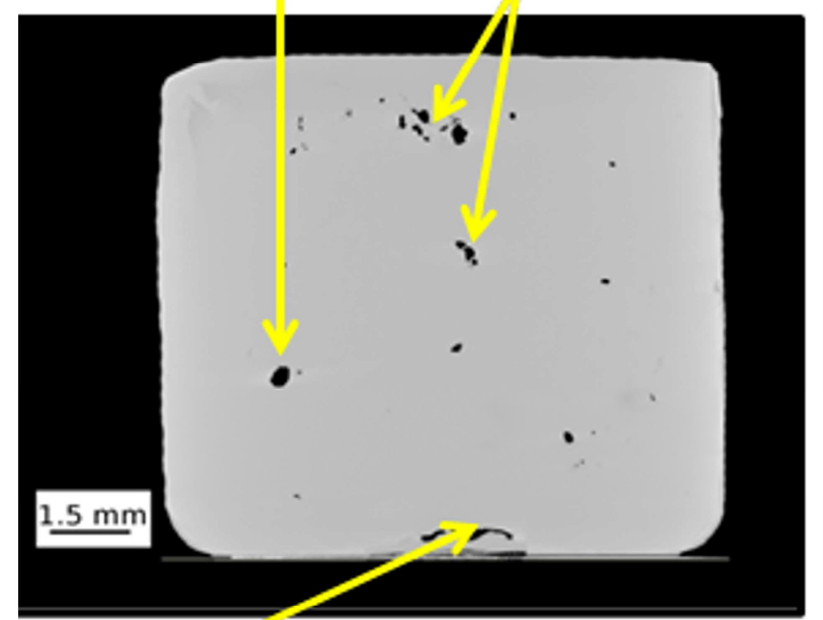

Crack
Pinhole with air trapped inside

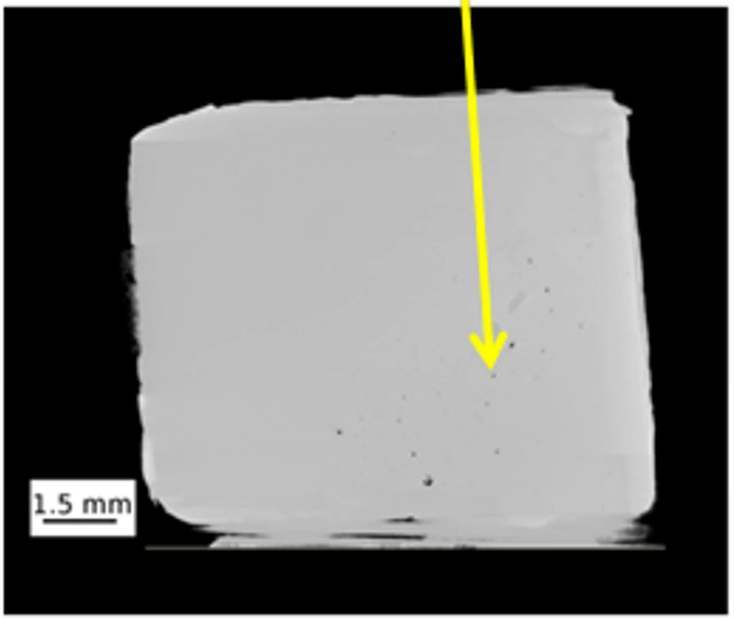




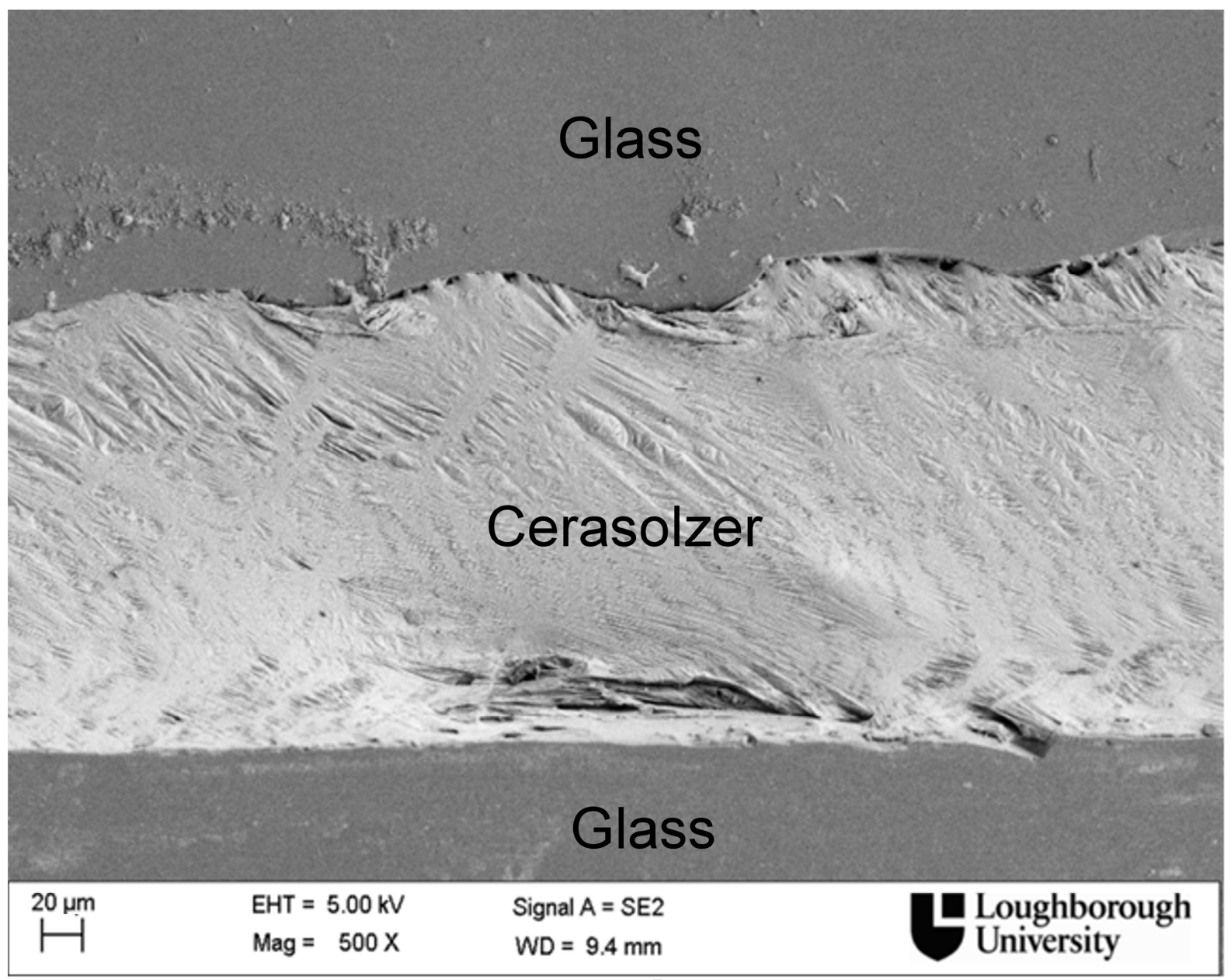




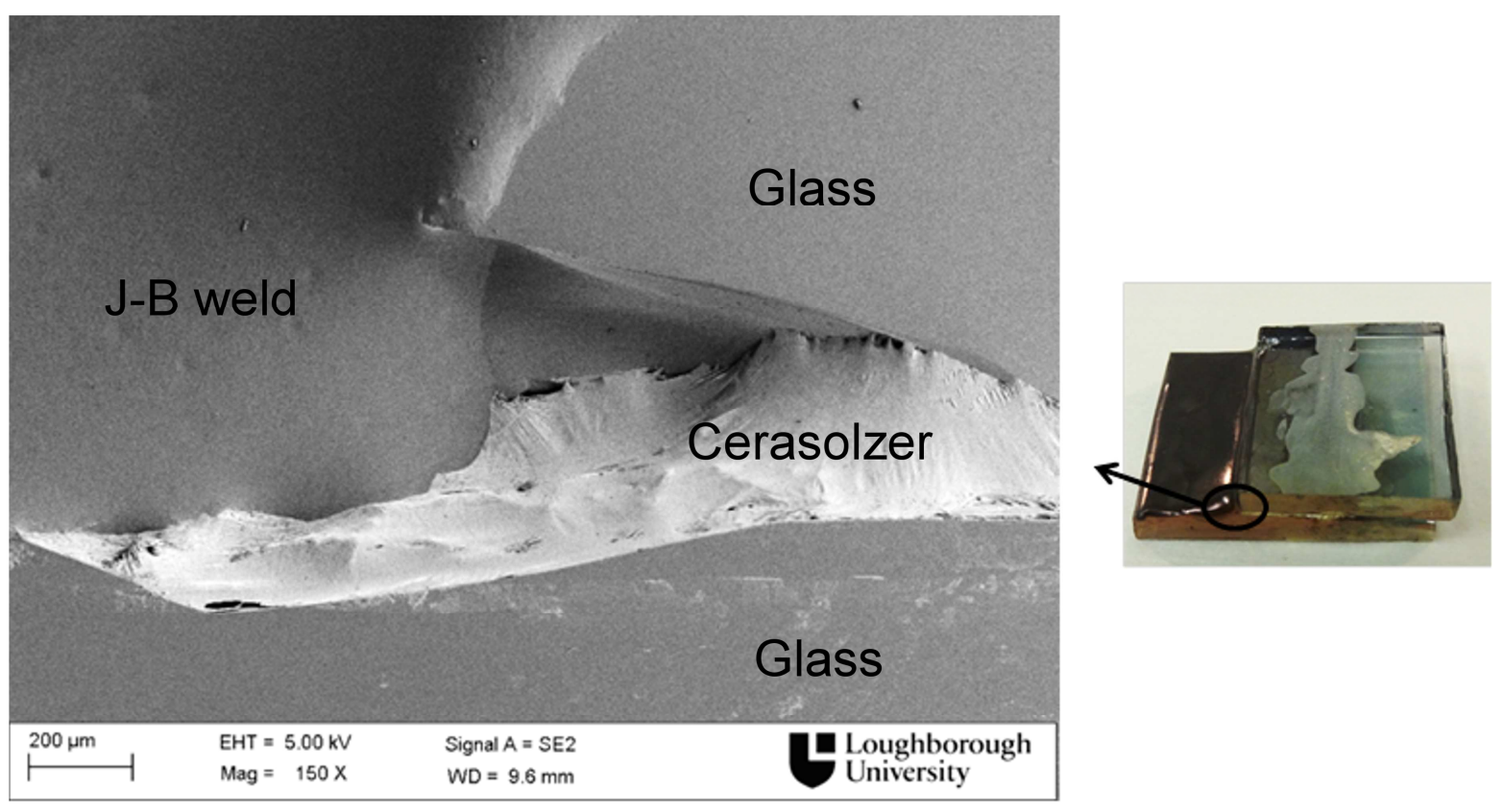




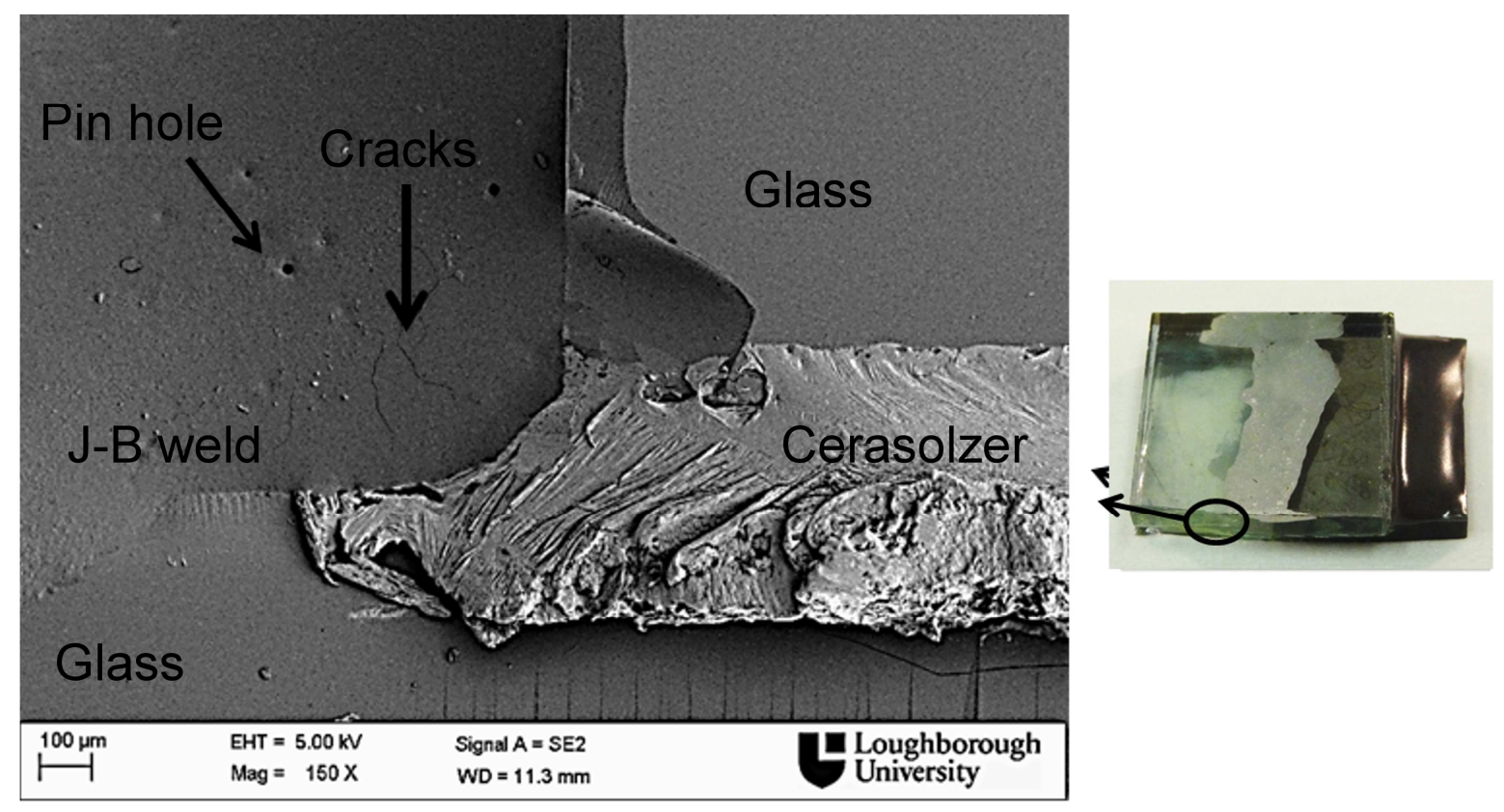




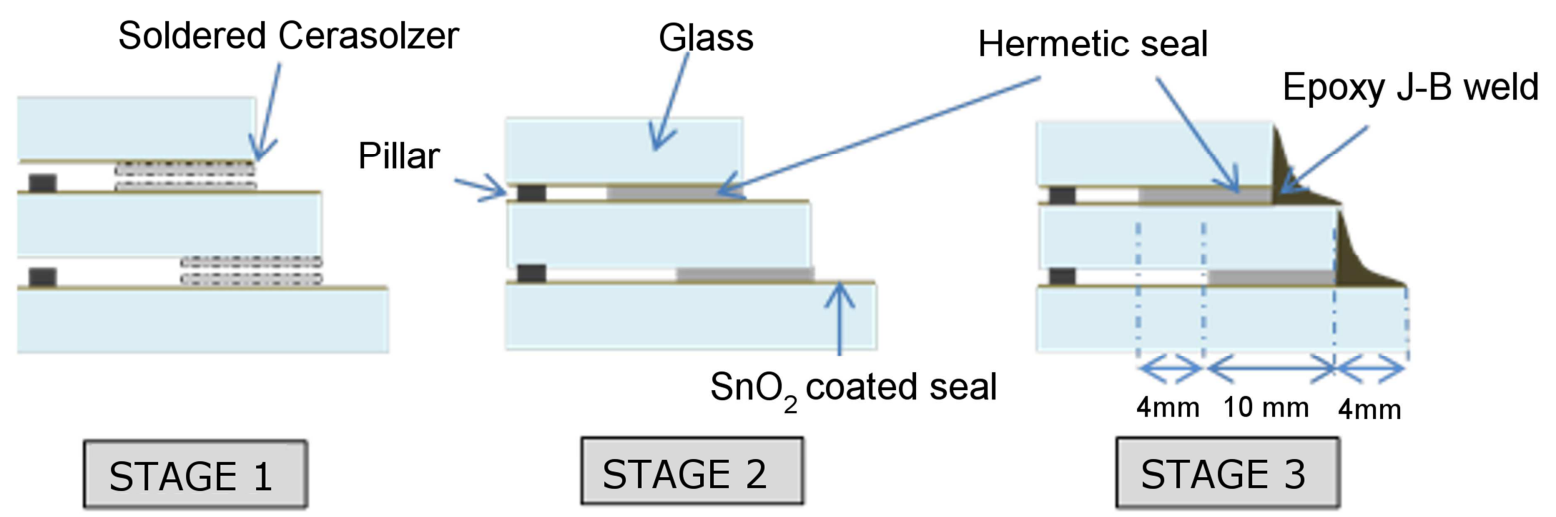




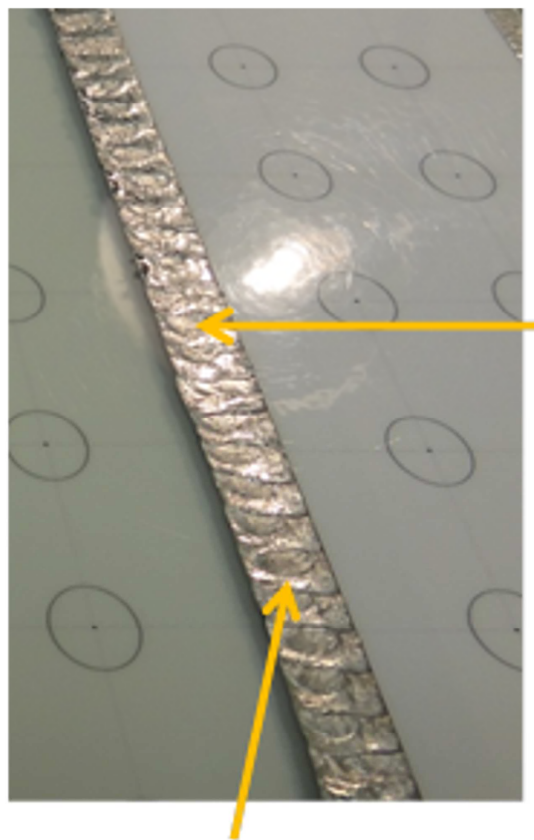

Primary edge seal with an approxiamte height of $1 \mathrm{~mm}$

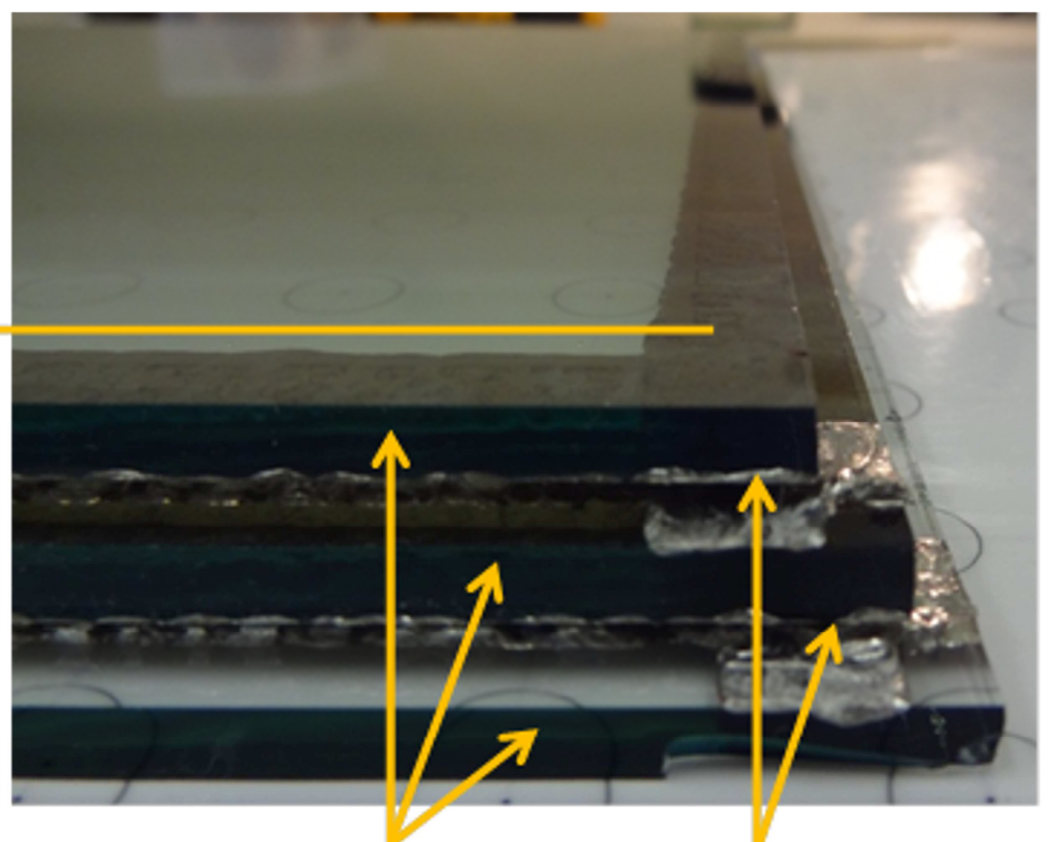

Three Glass sheets Three Glass sheets 


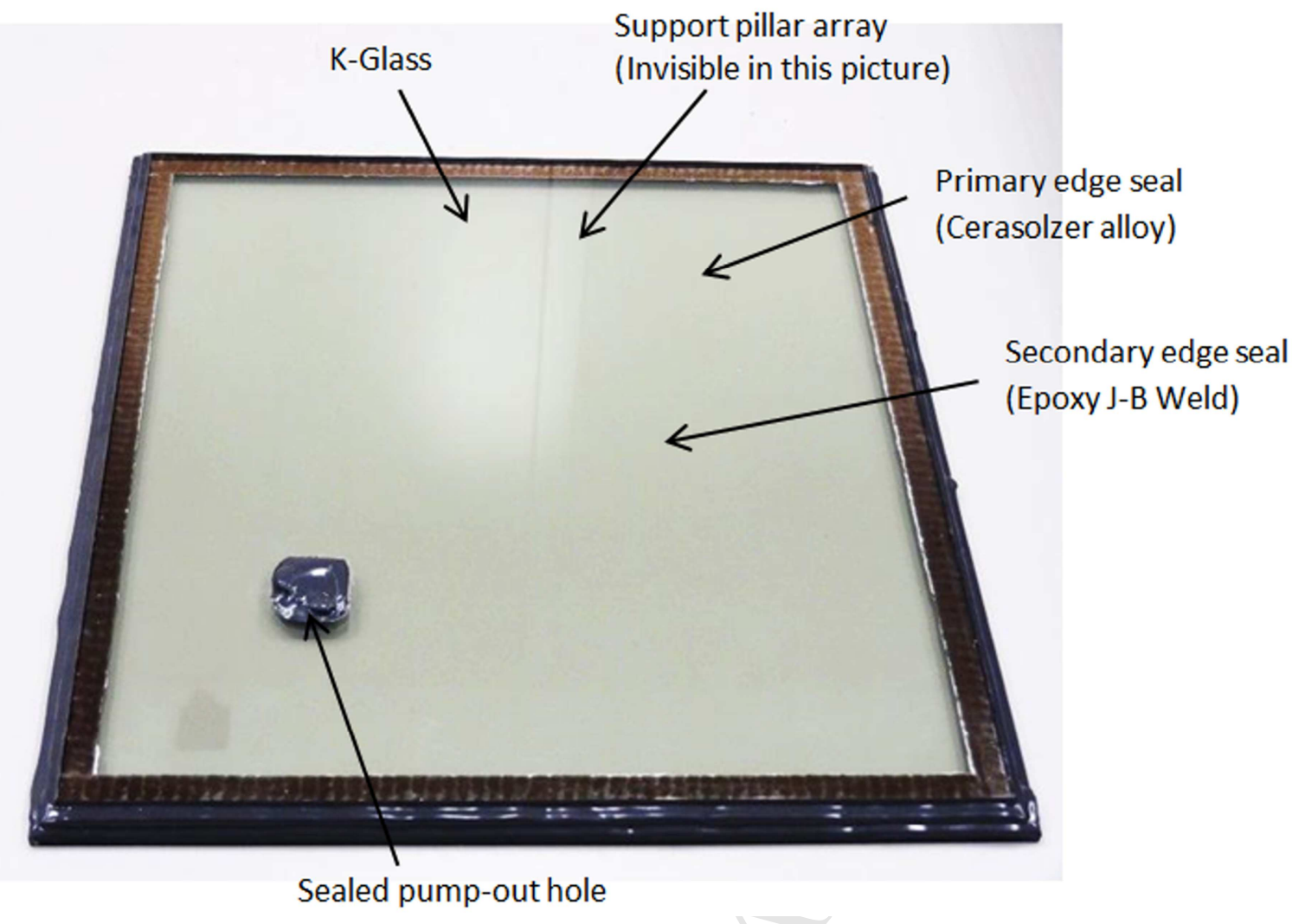




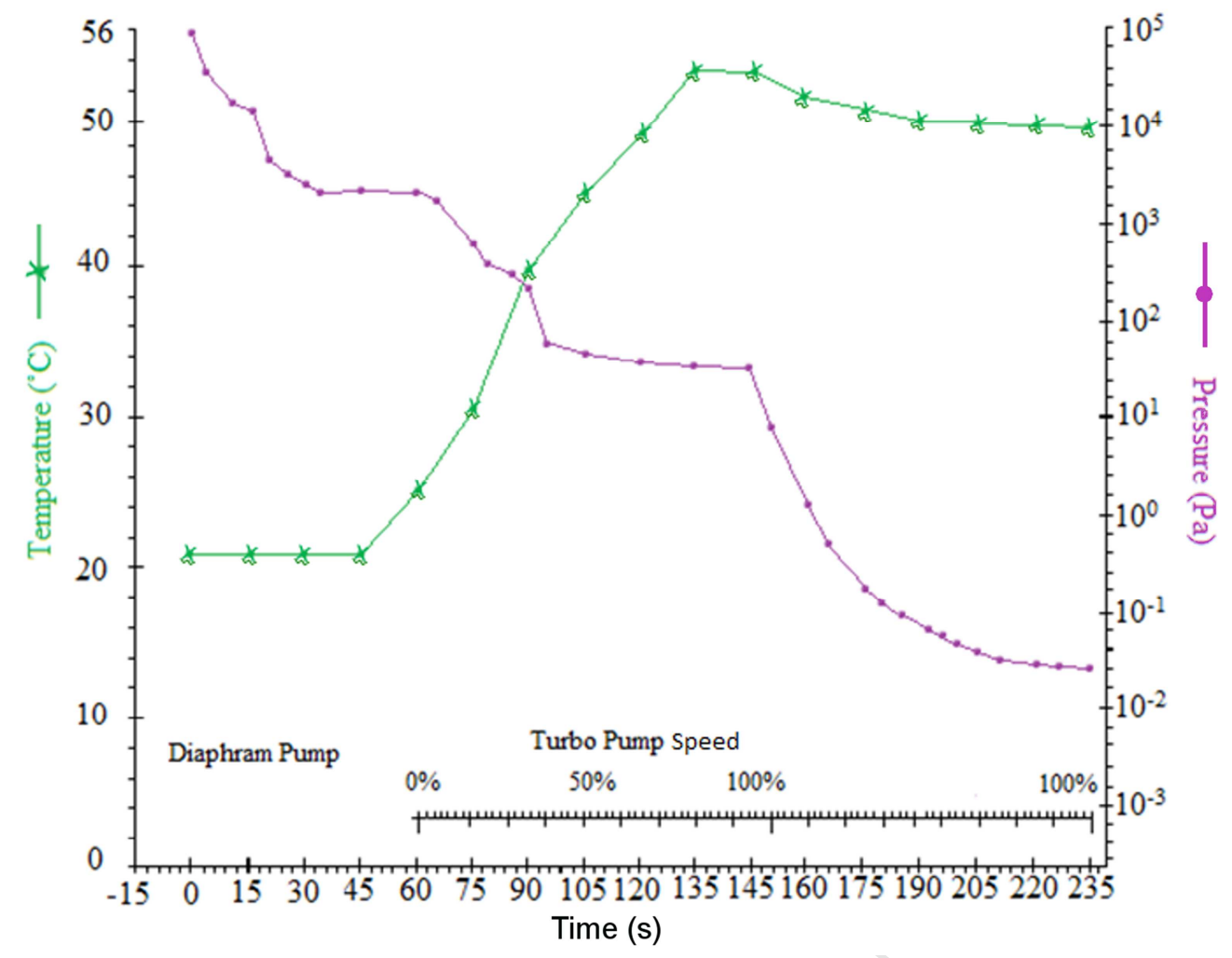




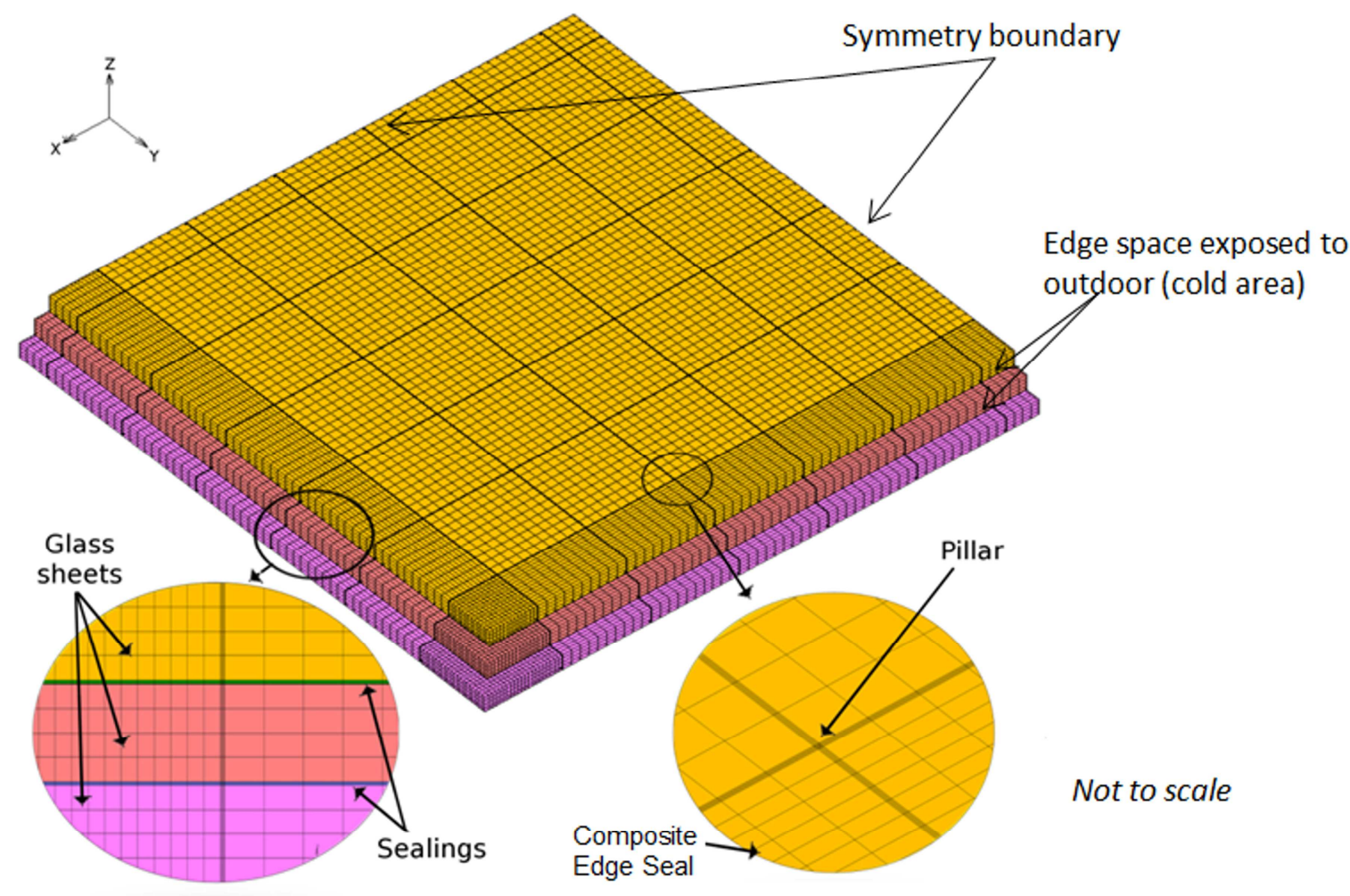



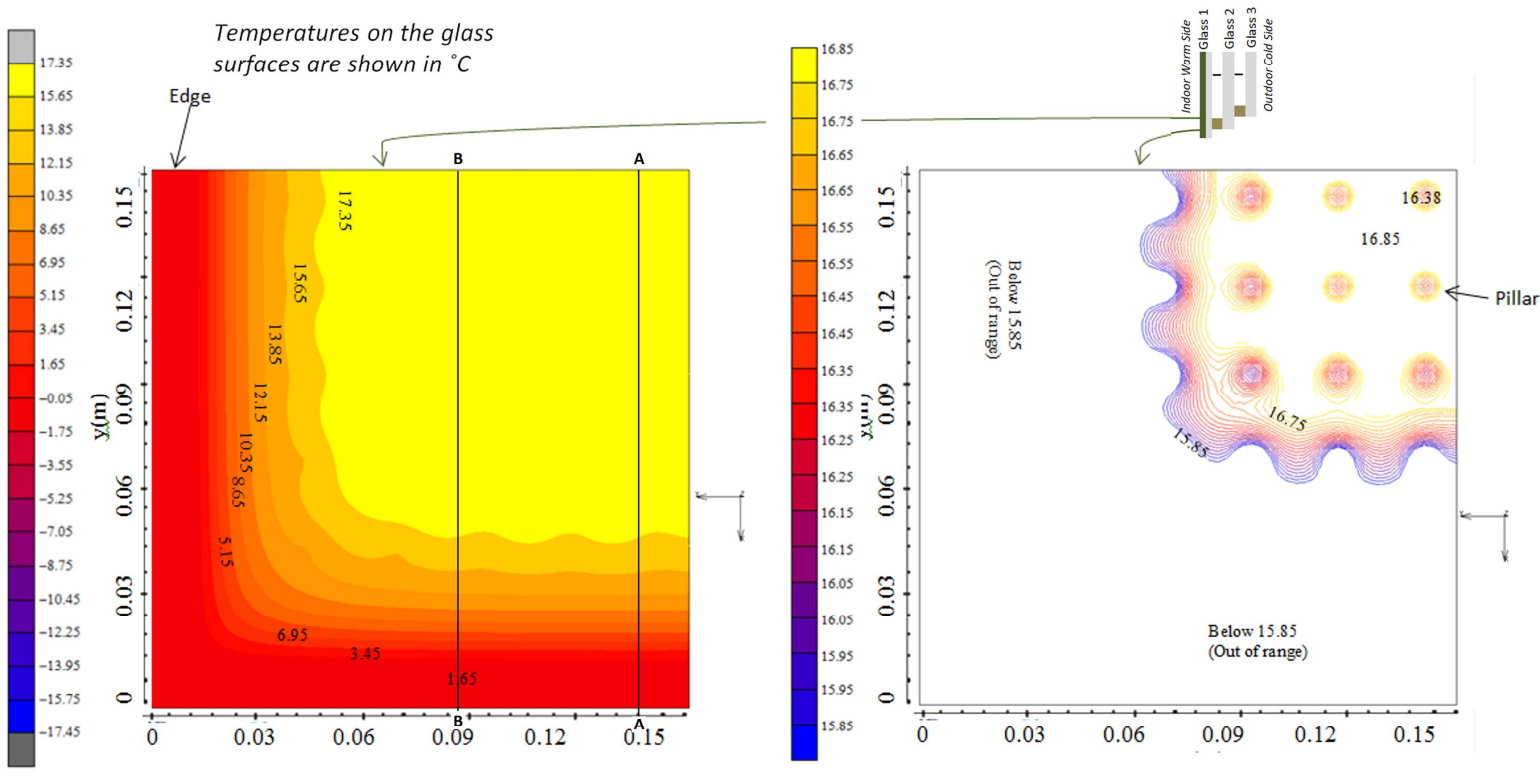


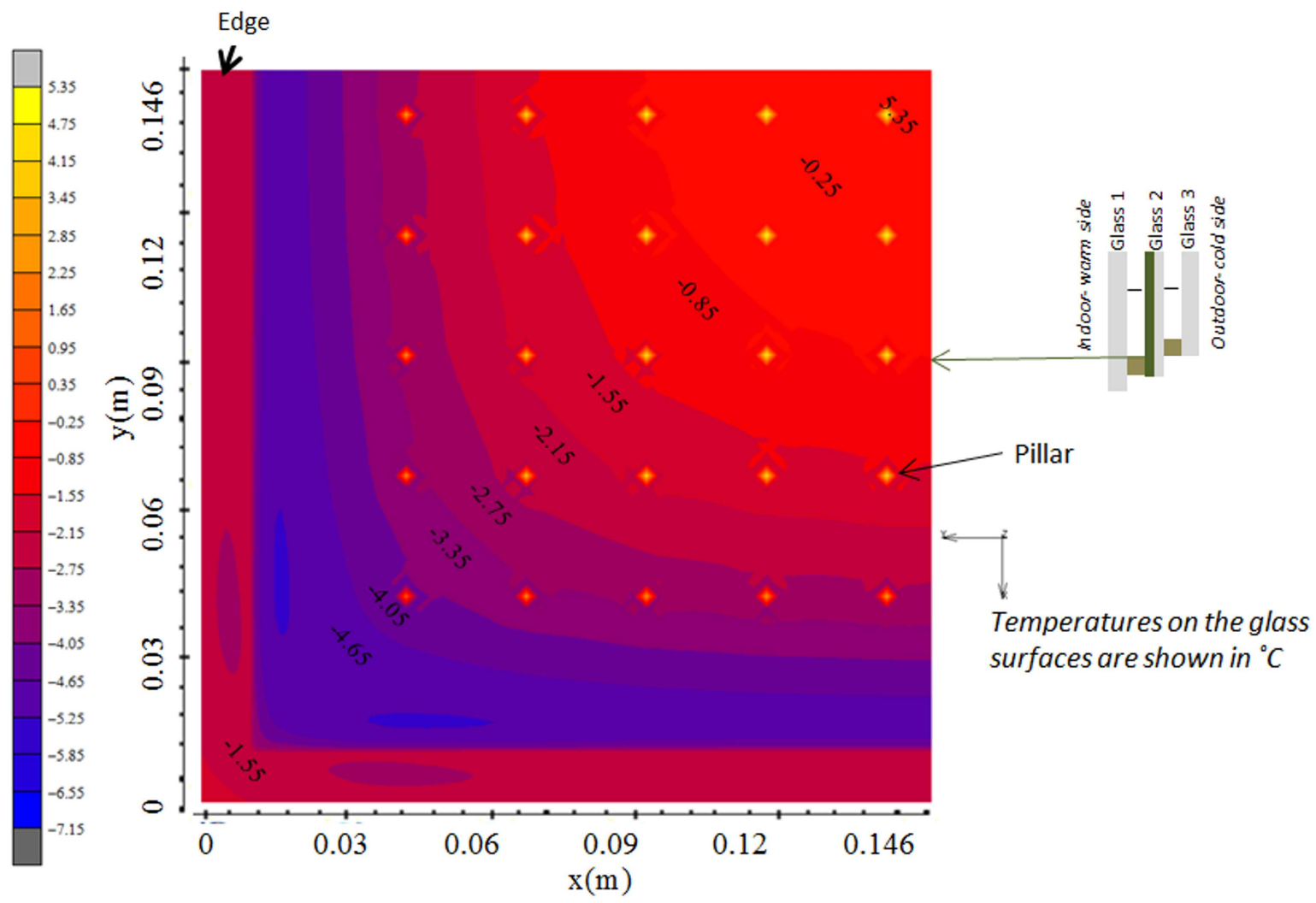




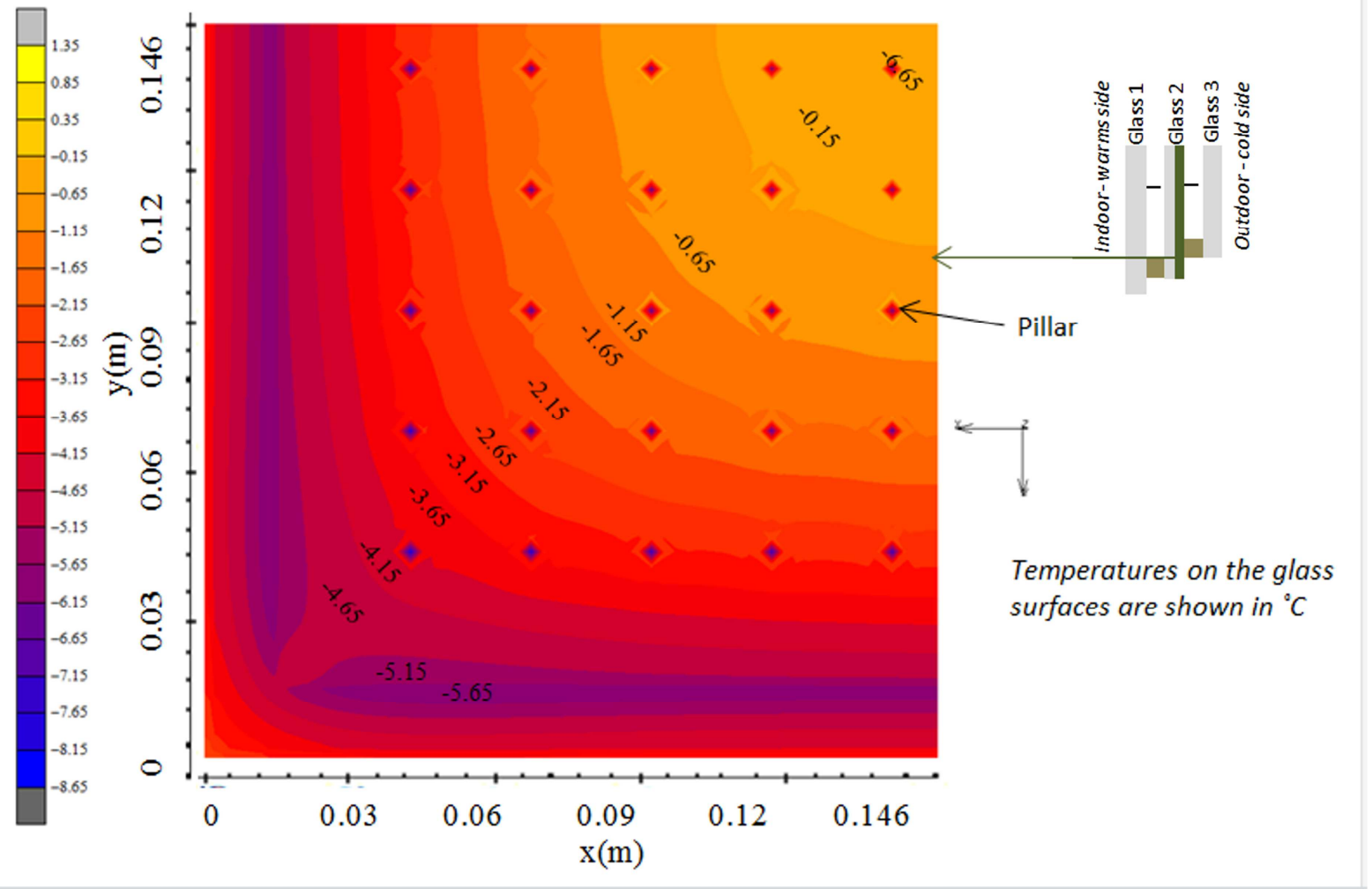




\section{ACCEPTED MANUSCRIPT}

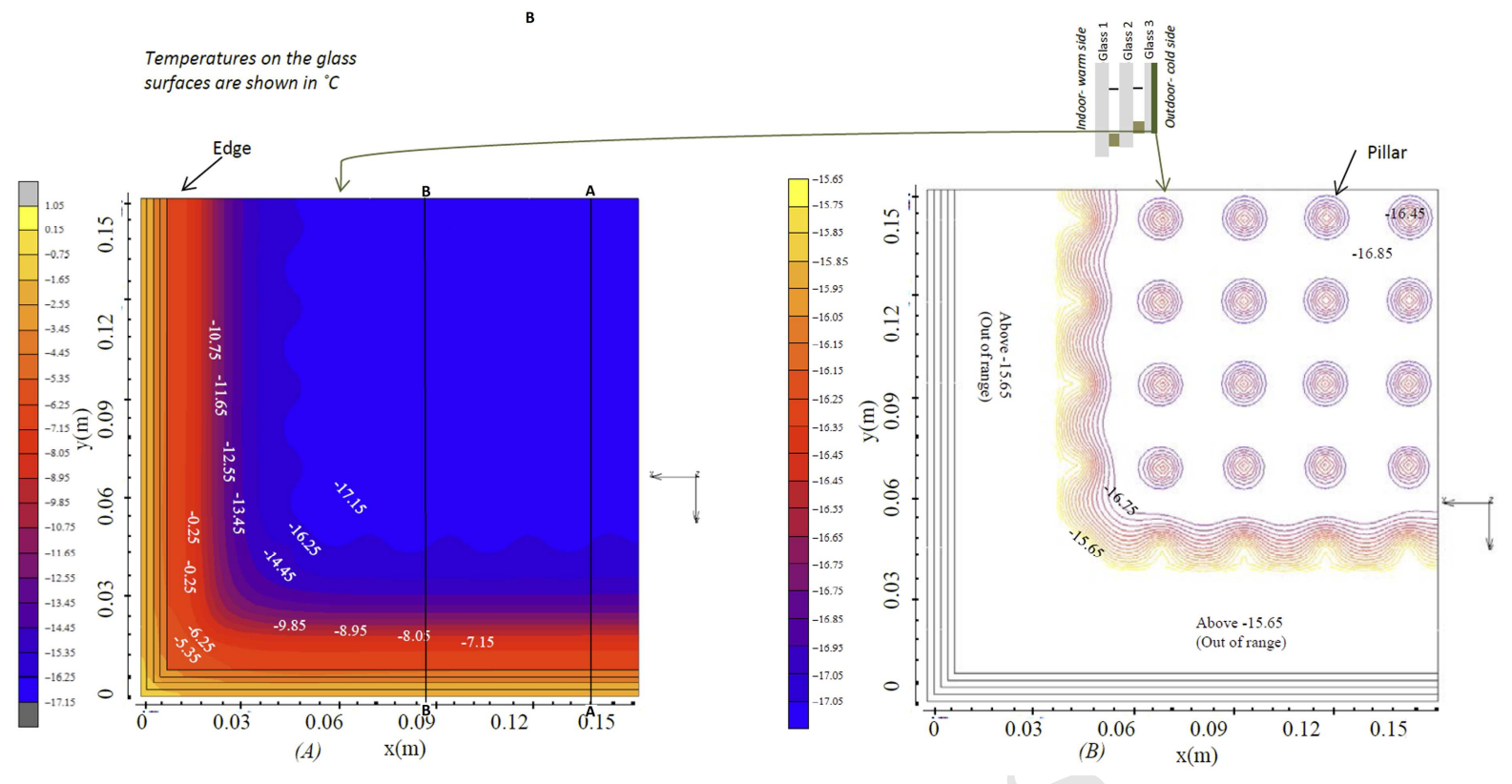




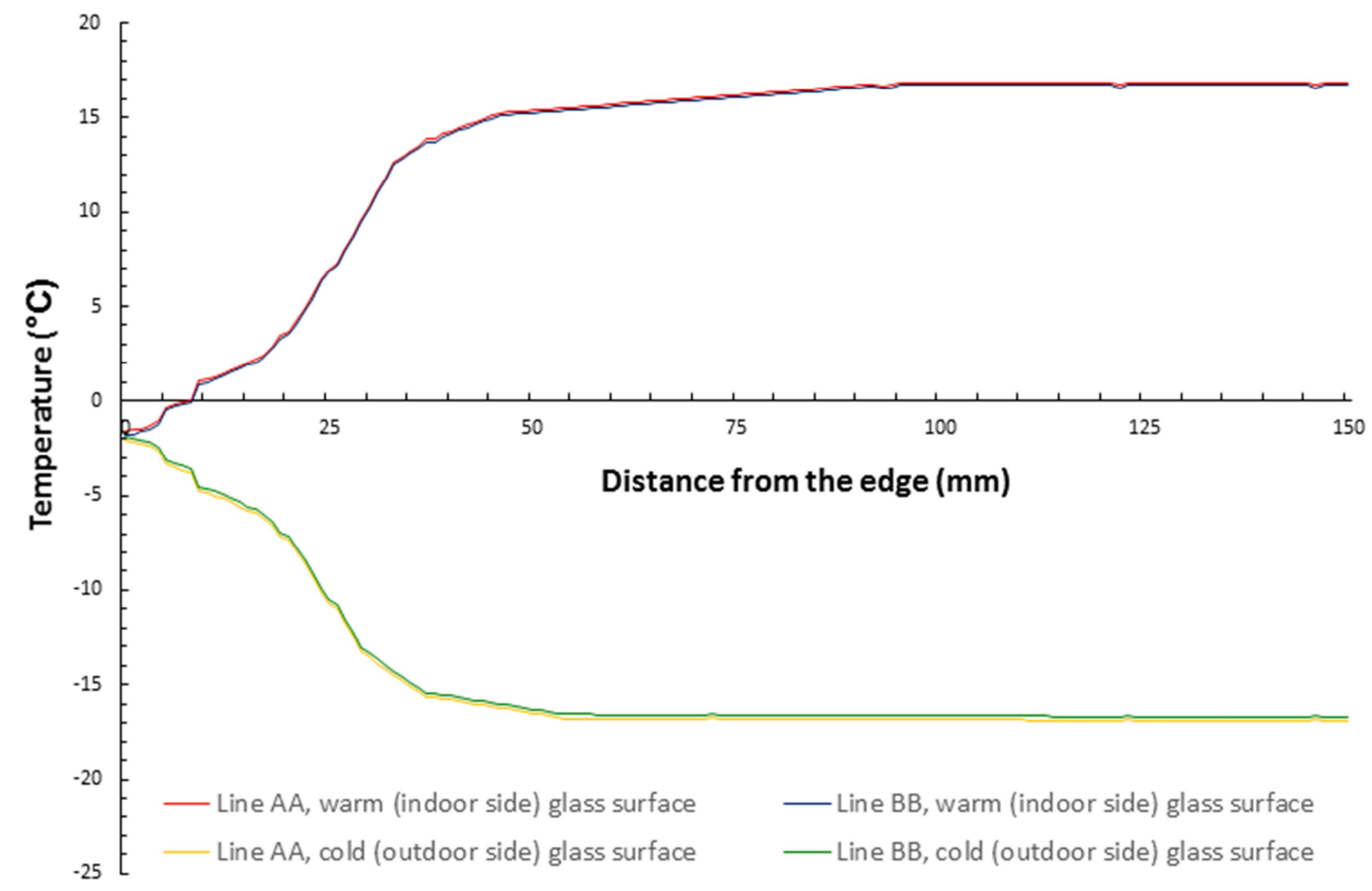




\section{Highlights}

- A new hermetic glass-sealing method for vacuum glazing was developed.

- The low-temperature edge sealing materials were analysed.

- A novel design and fabrication process was discussed.

- A vacuum pressure of $4.8 \times 10^{-2} \mathrm{~Pa}$ was achieved with triple-vacuum glazing.

- A centre-of-pane thermal performance was predicted to be $0.33 \mathrm{Wm}^{-2} \mathrm{~K}^{-1}$. 